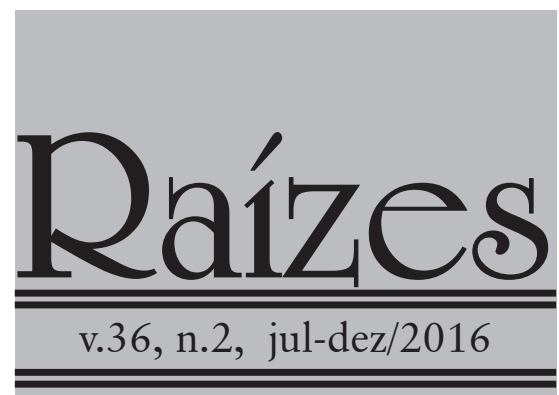

\title{
APORTES INSTITUCIONAIS NA IMPLEMENTAÇÃO DO PROGRAMA NACIONAL DE ALIMENTAÇÃO ESCOLAR NAS ESCOLAS ESTADUAIS DO MUNICÍPIO DE SANTA MARIA-RS
}

\author{
Rita Inês Paetzhold Pauli, Jéferson Réus da Silva Schulz, Bruna Tadielo Zajonz
}

\section{RESUMO}

O artigo mostra a dinâmica operacional do Programa Nacional de Alimentação Escolar (PNAE) nas escolas estaduais do município de Santa Maria-RS. Os procedimentos metodológicos compreendem, além da revisão da literatura especializada acerca das abordagens teóricas da Nova Economia Institucional (NEI), um estudo empírico de análise realizado a partir do emprego da técnica de documentação direta em 35,90\% das escolas estaduais do município, enfatizando as relações que envolvem os processos de compra e venda pelos representantes dos grupos sociais formais e informais. Os resultados inferem que a administração dos recursos do PNAE vem ocorrendo de forma eficiente, porém verificaram-se algumas falhas de governança e na percepção da qualidade da merenda escolar. Tais resultados poderão servir de base para o aprimoramento de políticas complementares e incursões específicas em elementos infraestruturais, permitindo uma melhor qualidade na merenda escolar e implicando em melhorias para todos os grupos sociais envolvidos.

Palavras-chave: Agricultura Familiar; PNAE; Mercados Institucionais; Segurança Alimentar e Nutricional.

\section{INSTITUTIONAL CONTRIBUTIONS IN IMPLEMENTING THE NATIONAL PROGRAM OF FOOD IN SCHOOLS STATE OF SANTA MARIA-RS MUNICIPALITY \\ ABSTRACT}

The article the operational dynamics of the National School Feeding Program (PNAE) in state schools of the city of Santa Maria-RS. The methodological procedures include, in addition to the review of the literature about the theoretical approaches of the New Institutional Economics (NEI), an empirical analysis performed from the use of direct documentation technique in $35,90 \%$ of state schools in the city, emphasizing relations involving the buying and selling processes by representatives of formal and informal social groups. The results infer that the administration of PNAE resources has taken place efficiently, but there were some failures in governance and perception of quality of school meals. These results could form the basis for the improvement of complementary policies and specific studies on infrastructural elements, enabling better quality in school meals and resulting in improvements for all social groups involved.

Key words: Family Farming; PNAE; Institutional markets; Food and Nutritional Security.

Professora Associada do Departamento de Ciências Econômicas da UFSM. E-mail: rita.pauli@gmail.com.

Mestrando no Programa de Pós-Graduação em Engenharia de Produção da UFSM. E-mail: jefersonschulz@gmail.com.

Mestranda no Programa de Pós-Graduação em Extensão Rural da UFSM. E-mail: brunabtz@gmail.com. 


\section{INTRODUÇÃO}

Sabe-se que o Programa Nacional de Alimentação Escolar (PNAE) possui como objetivo central atender a alimentação escolar em escolas públicas e demais entidades comunitárias, desde que conveniadas com o poder público, através da aquisição de alimentos da agricultura familiar. O Programa transfere recursos financeiros buscando atender aos alunos matriculados no âmbito da educação básica, que compreende a educação infantil, o ensino fundamental, o ensino médio e a educação de jovens e adultos.

O PNAE foi implantado em 1955, sendo a mais antiga política pública existente no Brasil. Nos últimos quinze anos (2009 a 2014), verificou-se um crescimento de 323,65\% nos recursos financeiros despendidos e um aumento de $14,36 \%$ no número de alunos atendidos pelo Programa, em nível nacional. Em 2014, foram gastos R\$ 3.693 milhões, consolidando o Programa que é considerado não apenas um direito dos estudantes, mas também uma das estratégias de segurança alimentar e nutricional (SAN).

Desse modo, o Programa, a partir de diretrizes estabelecidas em leis e regulamentações formais, atua como um importante segmento institucional no âmbito do fortalecimento e do desenvolvimento da agricultura familiar na medida em que garante um mercado para os produtos desse gênero. De acordo com Schmitt e Grisa (2013), o Programa contribui para a construção de mercados institucionais para a agricultura familiar e também para a promoção da segurança alimentar e nutricional no Brasil.

A operacionalização do PNAE enquanto política pública é consideravelmente complexa, uma vez que envolve diversos setores do governo e da sociedade, tanto em nível municipal, quanto estadual e federal. Para que essa operacionalização ocorra de forma adequada, é imprescindível a existência de con- dições favoráveis nas diversas esferas envolvidas, seja com a alimentação escolar, seja com a agricultura familiar (VILLAR et al., 2013).

Segundo Silva (2011), a agricultura familiar brasileira contempla uma grande diversidade cultural, social e econômica, e pode variar desde o campesinato tradicional até a pequena produção modernizada. Ao encontro disso, Buainain, Romeiro e Guanziroli (2003) consideram a agricultura familiar como um universo profundamente heterogêneo e esta heterogeneidade, conforme os referidos autores, destaca-se em termos de disponibilidade de recursos, acesso ao mercado, capacidade de geração de renda e acumulação.

No que concerne ao desempenho da agricultura familiar, percebe-se que este reflete um conjunto amplo de condicionantes que perpassam por uma série de fatores, como a disponibilidade de recursos, a inserção socioeconômica, a localização geográfica, as oportunidades e a conjuntura econômica, as instituições e valores culturais da família, do grupo social e também do país (BUAINAIN; ROMEIRO; GUANZIROLI, 2003). Dessa forma, é imprescindível que se busque o fortalecimento e o desenvolvimento da agricultura familiar nas diversas esferas em que ela está condicionada e, para tanto, faz-se necessário reduzir os atritos e aumentar tanto a convergência quanto a sinergia entre os diversos níveis de intervenção do setor público, por meio da integração das políticas macroeconômica, agrícola e de desenvolvimento rural (Idem).

Em virtude da importância que os mercados institucionais e a segurança alimentar e nutricional representam no desenvolvimento e fortalecimento da agricultura familiar, bem como da necessidade de se garantir aos alunos que estão em formação uma alimentação saudável e segura, o presente estudo procura descrever e analisar a dinâmica da alimentação escolar no âmbito do PNAE na rede de escolas estaduais do município de Santa Maria-RS. 
Dessa forma, o objetivo central da pesquisa consiste em explicitar a dinâmica administrativa dos recursos do PNAE nas escolas estaduais do município e, para tal, mostra-se as ações e percepções da direção e responsáveis das escolas na operacionalização do PNAE vis a vis às diretrizes do Programa. O artigo inicia com a apresentação dos principais elementos teóricos da temática acerca dos mercados institucionais e segurança alimentar e nutricional; a segunda seção mostra os procedimentos metodológicos adotados que compreendem um estudo de caso específico delimitado pelas escolas estaduais do município de Santa Maria-RS; a terceira seção apresenta os resultados e descreve as normas estabelecidas pelo PNAE que norteiam o formato atual acerca das condicionalidades do Programa, com o intuito de confrontar as diretrizes contempladas com as ações específicas das escolas pesquisadas. Finalmente, a última seção apresenta a conclusão que descreve conjuntamente a análise dos pressupostos teóricos com os resultados obtidos com a pesquisa.

\section{FUNDAMENTAÇÃO TEÓRICA}

\subsection{MerCADOS InSTITUCIONAIS}

Surgido como um ramo recente da Teoria Econômica, a Nova Economia Institucional (NEI) passou a ser desenvolvida por volta da segunda metade do século XX e tem como um de seus principais expoentes Douglas North ${ }^{1}$, que coloca as instituições no centro do processo de desenvolvimento e evolução da sociedade (CONCEIÇÃO, 2002). Na análise feita por Conceição (2002, p. 128) acerca dos principais autores que deram suporte à NEI, como Ronald Coase, Oliver Williamson e Douglas North, o autor alude que "para esses autores, as instituições, ao se constituírem em mecanismos de ação coletiva, teriam como fim dar 'ordem' ao conflito e aumentar a eficiência". Medeiros (2001) menciona o conjunto de regras formais (como as leis e regulamentações), os constrangimentos informais (como as convenções e os códigos de condu- ta) e os mecanismos de promoção e de coerção das leis como sendo as instituições presentes em uma sociedade.

De acordo com Medeiros (2001, p. 5.1) "as instituições definem as 'regras do jogo da sociedade' onde os jogadores, isto é, as organizações (políticas, econômicas e sociais) atuam". Ao encontro disso, Saes (2000) corrobora que as organizações representam o comportamento cooperativo, sendo formadas por indivíduos que almejam um mesmo fim. De acordo com Zylbersztajn (2000), as organizações podem ser as empresas, as universidades, as cooperativas, as associações de produtores, etc., e no âmbito dos sistemas agroindustriais, são elas as estruturas que dão suporte ao funcionamento destes.

Uma definição de sistema agroindustrial que se encontra na literatura econômica é a proposta por Zylbersztajn (2000, p. 13), que entende o sistema agroindustrial "como um conjunto de relações contratuais entre empresas e agentes especializados, cujo objetivo final é disputar o consumidor de determinado produto". Na medida em que ocorrem relações contratuais entre os agentes, estas incorrem em custos específicos que a literatura econômica denomina como custos de transação. Estes custos são gerados em detrimento de uma série de fatores, os quais são: racionalidade limitada, incerteza, ambiente complexo, oportunismo dos agentes e especificidade dos ativos (FIANI, 2002).

Uma definição formal de custos de transação encontra-se em Fiani (2002, p. 269), que considera que os "custos de transação são os custos que os agentes enfrentam toda vez que recorrem ao mercado". O autor alude que custos de transação são os custos de negociar, redigir e garantir o cumprimento de um contrato.

$\mathrm{Na}$ medida em que na sociedade ocorrem transações ou relações contratuais entre os indivíduos, haverá assimetria de informações decorrente das incertezas, da racionalidade limitada dos agentes e da complexidade inerente ao ambiente em que essas transações se desenvolvem. Dessa forma, é possível 
atribuir às instituições um papel fundamental na redução das incertezas das transações que se sucedem entre os indivíduos na sociedade (MEDEIROS, 2001).

Simões (2014) pontua que as instituições, na medida em que são criadas pelos indivíduos, buscam estabilizar as relações de troca existentes por meio da redução das falhas de mercado, geradas, de acordo com Fiani (2002), pela racionalidade limitada, pelas incertezas, pelo ambiente complexo, pelo oportunismo e a pela especificidade dos ativos, pois esses fatores, somados, acarretam dificuldades significativas quando se contrata uma transação.

No contexto do desenvolvimento rural, compreender as organizações e, em especial, as instituições, pontua como um fator importante no âmbito dos sistemas agroindustriais, seja para traçar estratégias privadas, seja para estabelecer políticas públicas (ZYLBERSZTAJAN, 2000). Neste sentido, as políticas públicas que visam o desenvolvimento rural, instituídas pelo governo federal, se constituem em instrumentos importantes para a consolidação dos empreendimentos rurais (SILVA; SILVA, 2011).

Existem quatro principais condicionantes do desenvolvimento rural cuja situação deve ser levada em conta, juntamente com sua influência sobre a dinâmica da produção familiar, quando se pensa em políticas de desenvolvimento e promoção da agricultura familiar. São eles: os incentivos que os produtores têm para investir e produzir, a disponibilidade de recursos, o acesso aos mercados, insumos, informações e, por último, as instituições, que influenciam as decisões dos agentes e inclusive sua capacidade, possibilidade e disposição para produzir (BUAINAIN; ROMEIRO; GUANZIROLI, 2003).

Como destaca Arbage (2003), a decisão de plantar dos agricultores depende de uma diversidade de fatores, como a tradição familiar, as medidas de política agrícola e a existência de mercado para o produto. Garantir um mercado para os produtos da agricultura familiar é imprescindível e, nesta pers- pectiva, o governo federal vem desenvolvendo uma série de políticas que visam dar segurança aos produtores rurais e a seus respectivos empreendimentos familiares.

No contexto das políticas públicas de fortalecimento e desenvolvimento da agricultura familiar, surgem os mercados institucionais que, conforme sustentam Silva e Silva (2011), são mercados que apresentam diversas oportunidades para os empreendimentos da agricultura familiar. Dentre essas oportunidades estão: o fortalecimento dos processos sociais organizativos dos empreendimentos rurais; a possibilidade de comercializar produtos agroecológicos; e a possibilidade de diversificação produtiva com vistas a atender uma nova demanda que se faz presente (SILVA; SILVA, 2011).

Segundo Schimitt e Guimarães (2008, p. 8), "no Brasil, a comercialização de produtos da agricultura familiar por meio do mercado institucional é um fenômeno relativamente recente". Assim, este mercado garante a comercialização de parte da produção e abre possibilidades para o surgimento de empreendimentos associativos, de forma que possui linhas que servem como capital de giro para a compra da produção dos associados (SILVA; SILVA, 2011).

O mercado institucional engloba as compras governamentais de alimentos a serem utilizados em programas e organismos públicos, servindo como um potencial instrumento de promoção da agricultura familiar (SCHIMITT, 2005). Dessa forma, é fundamental o papel do Estado na criação de novos mercados, como o da alimentação escolar, atuando como um expoente essencial na proteção e estímulo à agricultura familiar, uma vez que “[...] um dos grandes estrangulamentos por que passa a produção familiar hoje no País é a falta de mercado para seus produtos, especialmente os alimentos, dada a forte restrição do poder de compra dos salários, em especial do salário mínimo [...]” (Instituto da Cidadania apud SCHIMITT, 2005, p. 80).

A compra institucional da agricultura familiar é, assim, parte de um processo que re- 
conhece a necessidade de se pensar em uma forma de produção de alimentos que atenda às demandas nutricionais da população e garanta a evolução social e econômica dos agricultores familiares, a partir de formas alternativas de produção e comercialização de alimentos (FNDE, 2014). Estas formas alternativas incluem a criação das cadeias curtas de produção e comercialização que aproximam a relação entre produtores e consumidores, fortalece as relações sociais, valoriza a diversidade produtiva e atende às necessidades das instituições públicas, possibilitando o acesso a alimentos saudáveis e de qualidade para a população, na perspectiva da promoção da segurança alimentar e nutricional (FNDE, 2014).

\subsection{SEGURANÇA ALIMENTAR E NUTRICIONAL E A ALI- MENTAÇÃO ESCOLAR}

Para Husenov et al. (2015, p. 1) "food security is one of the main challenges for governments and world leaders and for human populations, not least in developing countries”. O debate acerca da segurança alimentar e nutricional, também no Brasil, é atual e recorrente, principalmente quando considera segurança alimentar e nutricional como um instrumento de desenvolvimento econômico e social.

O Conselho Nacional de Segurança Alimentar e Nutricional (CONSEA) define a segurança alimentar e nutricional como sendo uma estratégia ou conjunto de ações que:

[...] consiste na realização do direito de todos ao acesso regular e permanente a alimentos de qualidade, em quantidade suficiente, sem comprometer o acesso a outras necessidades essenciais, tendo como base práticas alimentares promotoras da saúde, que respeitem a diversidade cultural e que sejam ambiental, cultural, econômica e socialmente sustentáveis (CONSEA, 2014).

Salienta-se que a segurança alimentar e nutricional, além de intersetorial e participativa, representa um importante papel no fortalecimento da agricultura familiar, na medida em que se preconiza a chamada soberania alimentar, conferindo soberania àqueles que praticam a agricultura familiar, uma vez que a estes é garantido o direito e a autonomia de decisão sobre o que produzir, para quem produzir e em que condições produzir (CONSEA, 2014). No que concerne à relevância delegada à soberania alimentar, Belik (2003) sustenta que "a soberania alimentar atribui uma grande importância à preservação da cultura e aos hábitos alimentares de um país”.

De acordo com Belik (2003), o conceito de segurança alimentar e nutricional leva em consideração três principais aspectos, os quais são: quantidade, qualidade e regularidade no acesso aos alimentos. No que se refere à quantidade, a atenção deve recair sobre o abastecimento adequado de uma determinada população, que, segundo Vieira et al. (2007, p. 9) “[...] pode ser obtida por meio do aumento da renda familiar, conjuntamente com uma oferta adequada de alimentos via aumento da produção interna ou aumento da importação de alimentos".

Acerca do aspecto qualidade, Belik (2003, p. 14) aponta que "a alimentação disponível para o consumo da população não pode estar submetida a qualquer tipo de risco por contaminação, problemas de apodrecimento ou outros decorrentes de prazos de validade vencidos". Conforme o referido autor, quando se fala em qualidade do alimento, deve-se considerar também a forma como este é consumido pelas pessoas, sendo necessário que o consumo ocorra de forma digna, de modo que os indivíduos disponham de um ambiente limpo para realizar suas refeições, com talheres e de acordo com as normas tradicionais de higiene.

O último aspecto apontado por Belik (2003), a regularidade no acesso aos alimentos, leva em consideração a necessidade de garantir seu acesso constante, de forma que as pessoas alimentem-se ao menos três vezes por dia. O autor enfatiza ainda que uma população que tenha acesso restrito aos alimentos não está isenta do risco de incorrer em insegurança alimentar e nutricional. 
Paulilo e Almeida (2005) afirmam que a segurança alimentar e nutricional é um instrumento de inclusão social e deve ser tratada de forma ampla, observando, além das condições de saúde dos indivíduos, higiene dos alimentos e autenticidade da produção, também no que diz respeito à elevação das condições de renda e emprego dos pequenos agricultores familiares e demais trabalhadores rurais envolvidos no processo de produção dos alimentos. Para esses autores, a noção de segurança alimentar e nutricional abrange todos os segmentos que produzem e distribuem alimentos, de forma que perpassa pela agricultura, pela indústria, pelo setor de serviços e também pelo comércio.

Dessa forma, deve-se considerar a importância que a intervenção do Estado assume nesse âmbito, uma vez que, em virtude da segurança alimentar e nutricional passar por diversos segmentos, poderá apresentar algum grau de assimetria de informações decorrente das inúmeras relações que são estabelecidas no decorrer do processo em sua integralidade. Acerca do papel do Estado em face dessas informações assimétricas, Pessanha e Wilkinson (2003, p. 268) aludem que:

A assimetria de informação que caracteriza certos atributos intrínsecos dos alimentos exige papel ativo do Estado no controle e fiscalização da qualidade dos produtos alimentícios, seja estabelecendo normas e padrões de segurança e informação obrigatórios, com sanções e penalidades no caso do não cumprimento das mesmas, seja atuando na fiscalização e na vigilância das normas e padrões estabelecidos [...].

No intuito de aproximar o consumo de alimentos e a produção de pequenos agricultores de base familiar, com vistas a incentivar um consumo de alimentos seguro, atendendo aos requisitos de quantidade, qualidade e regularidade propostos pelo conceito de segurança alimentar e nutricional, o Estado passa a atuar na criação de programas públicos alimentares, como é o caso do PNAE, de modo que esses programas possam atuar como fortes incentivos para minimizar o problema do consumo e da produção de alimentos, sendo possível em virtude da integração de políticas relacionadas à saúde da população de escolares e à criação de mercados para os agricultores familiares, inclusive com potencial para fomentar práticas de gestão ambiental (TRICHES; SCHNEIDER, 2010).

A conexão entre o PNAE e a segurança alimentar e nutricional se dá, conforme enfatizam Santos et al. (2014), na medida em que o Programa, enquanto uma política pública, abarca potencialidades para atender aos preceitos da segurança alimentar e nutricional, não só diretamente, mediante a oferta de alimentos de qualidade, mas também indiretamente, pelo incentivo à agricultura familiar, orgânica ou não, que é promotora do desenvolvimento regional sustentável e da soberania alimentar.

A reestruturação agroalimentar é uma discussão que envolve a literatura especializada mundial. Autores como Marsden (2012, p. 258) relacionam esses conceitos com a discussão espacial e regional.

[...] I would argue that the established sub-discipline of rural sociology should be seen partly as a crusading force in wider interdisciplinary environmental and sustainability science debates [...]. We have to reintroduce two major distinctive features of both past, and indeed future agri-food landscapes. These concern the distinctive and transcending role of the state and of space in the reconstitution of agri-food relations.

Na verdade, o PNAE se apresenta como um dos Programas basilares do Programa de Segurança Alimentar e Nutricional por ser capaz de promover a intersetorialidade de dois problemas cruciais que envolvem a realidade de países em desenvolvimento e que se referem à segurança alimentar e nutricional. 
Conforme Maluf (2009) existe um elo institucional entre a escola e a atividade de ensino e a agricultura de base familiar, sendo mediado pelos alimentos, ou seja, os bens alimentares, e pela alimentação, isto é, o modo como esses bens são apropriados.

\section{PROCEDIMENTOS METODOLÓGICOS DA PESQUISA}

O presente estudo de caso lançou mão da técnica de documentação direta, realizando-se um levantamento de dados no próprio local de ocorrência do fenômeno. Dessa forma, optou-se por uma pesquisa de campo que partiu de um levantamento bibliográfico com vistas a nortear os objetivos da pesquisa e a dar sustentação teórica ao tema abordado.

De acordo com Marconi e Lakatos (2009), a pesquisa de campo é aquela na qual o pesquisador busca coletar informações e/ou conhecimentos acerca de um problema para o qual se deseja chegar a uma resposta. Neste trabalho, utilizou-se o método quantitativodescritivo, em que foi realizado um estudo de avaliação do Programa Nacional de Alimentação Escolar na rede de escolas estaduais do município de Santa Maria-RS no ano de 2014. Cabe ainda ressaltar que a presente pesquisa, do ponto de vista de sua natureza, classifica-se como aplicada e, quanto ao seu objetivo, como descritiva.

Conforme Cervo e Bervian (1983), na pesquisa aplicada, o pesquisador é movido pela necessidade de contribuir para fins práticos, mais ou menos imediatos, de modo de que busca soluções para problemas concretos. Ainda de acordo com os referidos autores, este tipo de pesquisa pretende, além de alcançar a atualização de conhecimentos para uma nova tomada de posição, transformar em ação concreta os resultados de seu trabalho.

Nas pesquisas descritivas, como destacam Cervo e Bervian (1983), o pesquisador, sem interferir, dedica-se ao estudo de fatos e fenômenos do mundo físico e especialmente do mundo humano. Os autores aludem que nestas pesquisas procura-se descobrir, com a precisão possível, a frequência com que um fenômeno ocorre, sua relação e conexão com outros fenômenos, sua natureza e suas características.

Os dados primários foram coletados mediante aplicação de um formulário junto aos responsáveis pelo PNAE em cada escola visitada. Segundo Gil (2010), o formulário consiste em uma técnica de coleta de dados em que o pesquisador formula questões previamente elaboradas e anota as respectivas respostas. Para Marconi e Lakatos (2009), o formulário tem como característica principal o contato face a face entre o pesquisador e o entrevistado, sendo um roteiro de perguntas preenchido pelo entrevistador durante a entrevista.

Dessa forma, optou-se pelo uso de uma técnica padronizada de coleta de dados aplicando-se um formulário em 14 escolas, perfazendo 35,90\% do total de escolas estaduais do município de Santa Maria-RS², totalizando também $63,22 \%$ do total de alunos regularmente matriculados em 2014. O formulário, composto por 19 perguntas que se distribuíram entre abertas e fechadas, foi construído em eixos temáticos com o intuito de responder aos objetivos da pesquisa, abordandose tanto o perfil das escolas quanto a dinâmica operacional de realização do PNAE, sendo aplicado às pessoas-chave em cada uma das escolas visitadas. Ressalta-se ainda que a aplicação dos formulários ocorreu nos meses de abril a junho de 2014, sendo acompanhada de entrevistas semiestruturadas, na maioria dos casos com o responsável pelo setor financeiro de cada escola.

Buscou-se, junto à Oitava Coordenadoria Regional de Educação do Rio Grande do Sul (08-CRE), informações sobre o número de escolas estaduais em funcionamento no município de Santa Maria-RS com discentes regularmente matriculados, e os respectivos números de alunos em cada uma delas. Dessa forma, foi informada a existência de uma população finita de 39 elementos, que representa as 39 escolas da rede estadual de ensino em funcionamento na cidade de Santa Maria-RS, 
levando em consideração as matrículas regulares nos diferentes níveis de ensino.

Considerando-se as similaridades entre os elementos infraestruturais das escolas, verificados na pesquisa exploratória, optou-se por aplicar os formulários em 14 escolas que reúnem características representativas da totalidade das escolas estaduais no município e que aceitaram participar da pesquisa. Esse procedimento permite a apreensão mais fidedigna da dinâmica que envolve as compras institucionais, os elementos infraestruturais e a distribuição da merenda escolar nas diferentes escolas. Finalmente, deve-se ressaltar que Santa Maria-RS representa um campo profícuo de estudos na dinâmica do PNAE, considerando tratar-se de um município de porte médio que ocupa a terceira posição no que concerne ao número de matrículas da rede estadual do Rio Grande do Sul.

\section{RESULTADOS E DISCUSSÃO}

\subsection{OperacionalizaÇ̃̃O DO PNAE}

O Programa Nacional de Alimentação Escolar (PNAE), implantado em 1955 e gerenciado pelo Fundo Nacional de Desenvolvimento da Educação (FNDE), é um Programa do governo federal que visa contribuir para o crescimento, o desenvolvimento, a aprendizagem, o rendimento escolar dos estudantes e a formação de hábitos alimentares saudáveis, tendo em vista a oferta da alimentação escolar e ações de educação alimentar e nutricional. São atendidos pelo Programa os alunos de toda educação básica (educação infantil, ensino fundamental, ensino médio e educação de jovens e adultos) matriculados em escolas públicas, filantrópicas e em entidades comunitárias (conveniadas com o poder público), por meio da transferência de recursos financeiros (BRASIL, 2014).

Conforme o artigo 14 da Lei ${ }^{\circ} 11.947$ de 16 de junho de 2009, "do total dos recursos financeiros repassados pelo FNDE, no âmbito do PNAE, no mínimo 30\% deverão ser utilizados na aquisição de gêneros alimentí- cios diretamente da agricultura familiar e do empreendedor familiar rural ou de suas organizações”. Segundo o artigo $3^{\circ}$ da Lei $n^{\circ}$ 11.326 de 24 de julho de 2006:

Considera-se agricultor familiar e empreendedor familiar rural aquele que pratica atividades no mundo rural, atendendo, simultaneamente, aos seguintes requisitos: não detenha, a qualquer título, área maior do que 4 (quatro) módulos fiscais; utilize predominantemente mão de obra da própria família nas atividades econômicas do seu estabelecimento ou empreendimento; tenha renda familiar predominantemente originada de atividades econômicas vinculadas ao próprio estabelecimento ou empreendimento; tenha percentual mínimo da renda familiar originada de atividades econômicas do seu estabelecimento ou empreendimento, na forma definida pelo Poder Executivo; dirija seu estabelecimento ou empreendimento com sua família.

Para promover a conexão entre agricultura familiar e alimentação escolar, o PNAE estabelece os seguintes princípios e diretrizes: alimentação saudável e adequada; universalidade do atendimento e direito à alimentação escolar; participação da sociedade no controle social; inclusão da educação alimentar e nutricional no processo de ensino e aprendizagem; e desenvolvimento sustentável, que significa adquirir gêneros alimentícios diversificados e produzidos localmente.

No funcionamento do PNAE, no que se refere aos participantes do processo de aquisição, a compra dos alimentos é delegada às Entidades Executoras, que compreendem secretarias estaduais de educação, prefeituras, escolas e demais unidades vinculadas. O processo de venda exige que os participantes (vendedores) estejam inseridos no Programa Nacional de Fortalecimento da Agricultura Familiar (PRONAF) e distingue dois grupos: um formal, que é detentor de Declaração de Aptidão ao PRONAF (DAP Jurídica) agregando cooperativas e associações de agricultores familiares; e um informal, detentor de Declaração de 
Aptidão ao PRONAF (DAP Física) que comporta grupos de agricultores familiares.

O processo de aquisição dos alimentos ocorre com o auxílio de Entidades Articuladoras, como o Sindicato dos Trabalhadores Rurais (STR), a Empresa de Assistência Técnica e Extensão Rural (EMATER), o Sindicato dos Trabalhadores Rurais da Agricultura Familiar (SINTRAF), ou entidades credenciadas pelo Ministério do Desenvolvimento Agrário para emissão de DAP. Essas Entidades Articuladoras têm a função de intermediar a negociação entre o produtor rural e as Entidades Executoras. No decorrer do processo, todas as partes envolvidas devem cumprir as etapas propostas pelo programa. Esse processo é apresentado de modo simplificado na Figura 1.

FiguRA 1 - REPRESENTAÇÃO SIMPLIFICADA DO PROCESSO DE COMPRA E VENDA PELOS GRUPOS FORMAL E INFORMAL NO PNAE.

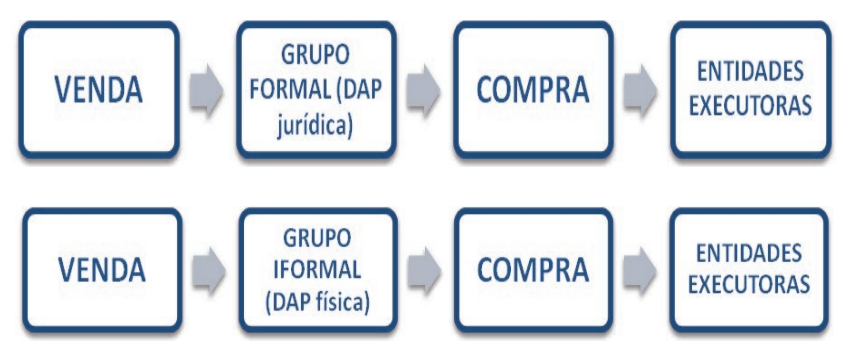

Fonte: Elaborado pelos autores.

A elaboração do cardápio da alimentação escolar é delegada a um nutricionista que deve respeitar a cultura alimentar da localidade, os produtos produzidos pelos agricultores familiares da região e prezar por uma alimentação saudável e adequada. Através da chamada pública, as Entidades Executoras publicam a demanda necessária de gêneros alimentícios provenientes da agricultura familiar. A publicação da chamada pública é realizada em jornais locais ou em murais públicos, e cabe aos agricultores e suas organizações observarem o prazo estipulado.

O preço de referência é determinado através da realização de três orçamentos que são elaborados conforme uma pesquisa de mercado no varejo do comércio local, dando prioridade às feiras de agricultura familiar. Esses preços devem ser atualizados semestralmente e não podem ser inferiores aos preços dos produtos cobertos pelo Programa de Garantia de Preços para Agricultura Familiar (PGPAF).

Posterior à determinação do preço, a Entidade Executora elabora o projeto de venda, em que consta a identificação dos fornecedores participantes e seus produtos, juntamente da descrição do mecanismo de distribuição dos produtos. O recebimento do projeto de venda deve ser acompanhado mediante apresentação da seguinte documentação: grupos informais - Declaração de Aptidão ao PRONAF (DAP física), Cadastro de Pessoas Físicas (CPF) de cada agricultor participante e projeto de venda; grupos formais - Declaração de Aptidão ao PRONAF (DAP jurídica), Cadastro Nacional de Pessoa Jurídica (CNPJ), cópias das certidões negativas junto ao Instituto Nacional do Seguro Social (INSS), Fundo de Garantia do Tempo de Serviço (FGTS), Receita Federal e Dívidas Ativas da União, cópia do estatuto e projeto de venda.

A seleção do projeto de venda é realizada pela Entidade Executora, dando prioridade a agricultores e cooperativas locais, de modo que cada produtor rural poderá vender até $\mathrm{R} \$ 9.000,00$ por DAP/ano e deve atender à legislação sanitária. Tendo sido cumpridos estes pré-requisitos, assina-se o contrato, em que se estabelece o cronograma de entrega do produto, bem como a data de pagamento dos agricultores familiares ou cooperativas.

Por fim, realiza-se o termo de recebimento, atestando-se que os produtos entregues estão de acordo com o cronograma previsto no contrato e dentro dos padrões de qualidade exigidos. Este termo deve ser assinado pela Entidade Executora e pelo grupo fornecedor e, no caso de grupo informal, deve conter também a ciência da Entidade Articuladora. As etapas a serem cumpridas conforme as normas do Programa estão simplificadas na Figura 2. 
FiguRA 2 - REPRESENTAÇÃO DO PROCESSO LICITATÓRIO NO PNAE.

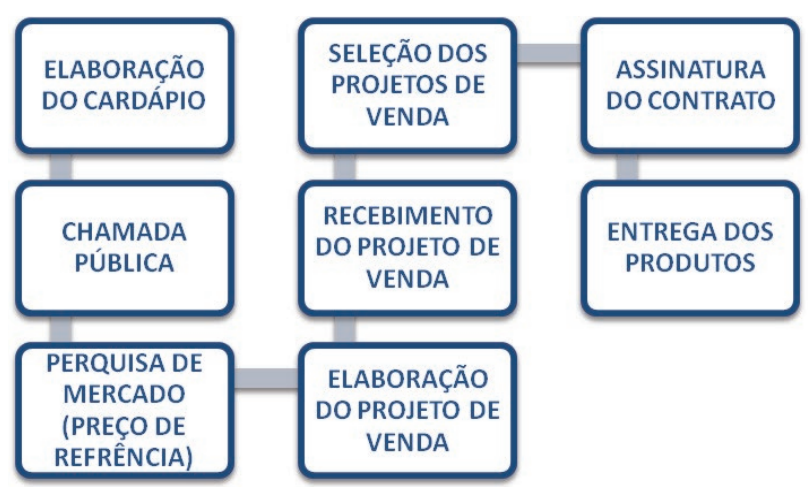

Fonte: Elaborado pelos autores.

O cálculo dos valores monetários repassados às prefeituras e estados, a cada ano, é realizado tendo por base o número de alunos matriculados segundo o Censo Escolar do ano anterior ao do atendimento. Isto significa que os recursos destinados para merenda escolar no ano de 2014 foram calculados com base no número de alunos matriculados no ano de 2013. Atualmente, o valor que a União repassa aos estados e municípios por dia letivo para cada aluno é definido de acordo com a etapa e modalidade de ensino (creches: $\mathrm{R} \$ 1,00$; pré-escola: R\$ 0,50; escolas indígenas e quilombolas: R\$ 0,60; ensino fundamental, médio e educação de jovens e adultos: R $\$ 0,30$; ensino integral: R \$ 1,00; alunos do Programa Mais Educação: R\$ 0,90; alunos que frequentam o Atendimento Educacional Especializado no contraturno: R\$ 0,50) (BRASIL, 2014).

Para realizar o cálculo do valor repassado às Entidades Executoras, consideram-se 200 dias letivos, os quais, pela forma como é feito o repasse (10 parcelas mensais), visam cobrir 20 dias letivos a cada mês, iniciando pelo mês de fevereiro. No cálculo, o valor total a ser recebido por cada Entidade Executora é encontrado através da multiplicação de três variáveis: o número de alunos matriculados segundo o Censo Escolar do ano anterior, o número de dias letivos e o valor per capita da alimentação escolar. O repasse é feito diretamente aos estados e municípios, com base no Censo Escolar realizado no ano anterior ao do atendimento (Brasil, 2014).

Devido ao elevado número de escolas e alunos na rede estadual de ensino, o governo do estado do Rio Grande do Sul repassa a verba recebida do governo federal diretamente para as escolas, que realizam as compras dos gêneros alimentícios para execução do cardápio elaborado pelas nutricionistas da Secretaria da Educação (SEDUC). A forma de repasse é a descentralizada, ou escolarizada como é mais conhecida.

Sobre a gestão escolarizada, encontrase a seguinte definição:

\begin{abstract}
Denomina-se gestão escolarizada o processo pelo qual o município, estado ou Distrito Federal repassa, diretamente as suas escolas, os recursos recebidos do FNDE. Nesse caso, são as próprias escolas que administram os recursos, fazendo as compras dos gêneros alimentícios a serem usados na alimentação escolar. (MINISTÉRIO DA EDUCAÇÃO, 2006, p. 39).
\end{abstract}

O PNAE é acompanhado e fiscalizado diretamente pela sociedade, por meio dos Conselhos de Alimentação Escolar (CAE), pelo Fundo Nacional de Desenvolvimento da Educação (FNDE), pelo Tribunal de Contas da União (TCU), pela Controladoria Geral da União (CGU) e pelo Ministério Público (BRASIL, 2014).

\subsection{Procedimentos E REALIZAÇÃO DO PNAE NAS escolas estaduais de Santa Maria-RS}

Os resultados da pesquisa indicam que das quatorze escolas visitadas, o número de alunos totaliza 13.882. A idade das escolas gravita entre 113 da mais antiga, e 23 da mais jovem, com uma média de 52 anos. Os representantes das escolas informaram que todos os alunos regularmente matriculados têm acesso à merenda escolar, isto é, a alimentação escolar é fornecida em todos os níveis de ensino.

Das escolas visitadas, treze dos entrevistados afirmam adquirir os produtos da alimentação dos alunos de cooperativas, principalmente da Cooperativa Regional da Reforma Agrária Mãe Terra (COOPERTERRA). Em apenas uma das escolas verifica-se que a aquisição dos produtos da alimentação escolar é 
proveniente da Cooperativa Central de Desenvolvimento Rural (COOPERCEDRO).

A pesquisa mostra que somente em uma escola os produtos da alimentação escolar são adquiridos diretamente de produtores rurais. Os entrevistados afirmam que há pouco interesse dos produtores da cidade em fornecer alimentos para alimentação escolar, fato decorrente do excesso de burocratização enfrentado tanto pelos produtores quanto pelas próprias escolas no processo de adequação às normas do PNAE.

Em cinco das escolas visitadas os respondentes informaram que já houve problemas com relação aos produtos adquiridos. Em uma delas, o responsável afirma que o problema teria ocorrido com o prazo de validade dos produtos, mas que, após constatada a irregularidade, a entidade fornecedora ressarciu a escola. Em outras duas escolas, o problema apontado foi com relação ao recebimento dos produtos, que teria decorrido da falta de documentação do fornecedor, não havendo necessidade das escolas serem ressarcidas. Nas outras duas escolas, os entrevistados afirmaram que os produtos recebidos apresentavam baixa qualidade, de modo que, em uma das escolas houve o ressarcimento necessário e na outra não. Na última escola, o problema apresentado é referente ao recebimento de produtos estragados, contudo, após reclamação por parte dos responsáveis, a escola foi ressarcida.

Com relação ao questionamento referente ao tipo de produtos que são utilizados na composição de parte da preparação da merenda escolar: a) em quatro escolas verifica-se que a maioria dos produtos direcionados à alimentação dos alunos é in natura; b) em duas escolas a composição da maior parte dos produtos é semi industrializada e industrializada; c) noutras duas escolas os produtos preponderantemente utilizados são in natura e semi industrializados; d) em quatro escolas a maior parte dos produtos adquiridos são semi industrializados e, e) em duas escolas a maioria dos produtos utilizados para a merenda escolas são in natura e industrializados.
Em todas as escolas observa-se que o valor destinado à alimentação escolar para produtos de origem da agricultura familiar atende ao limite mínimo de 30\%. Sobre os três orçamentos previstos nas normas no PNAE, obteve-se o seguinte resultado: a) onze das escolas os realizam e, b) três escolas não os realizam. As escolas que não realizam os três orçamentos previstos justificam que tal fato decorre da falta de opções de compra e de concorrência, uma vez que uma das principais dificuldades apontadas neste quesito é a falta de interesse dos produtores em fornecer os produtos. Isto decorreria em virtude da burocratização intrínseca ao processo.

No que diz respeito à orientação de valores monetários proposta para cada nível de ensino pelas diretrizes do Programa, os resultados revelam que nove das escolas visitadas seguem tal orientação e outras cinco não a seguem. Os entrevistados de todas as escolas informam que os recursos da merenda são aplicados de forma homogênea, com vistas a contemplar de maneira igualitária a todos os alunos.

Os valores monetários que cada escola recebe para aplicar na merenda dos alunos são proporcionais ao número de alunos matriculados de acordo com o Censo Escolar do ano anterior ao do recebimento. As escolas com maior número de alunos recebem um valor monetário maior para aplicar na merenda escolar no âmbito do PNAE.

Pode-se observar a insatisfação informada em 71,43\% das escolas com relação à metodologia do cálculo dos valores monetários a serem repassados para a aquisição da merenda escolar. Neste sentido, julgam que a metodologia deveria ser alterada, de forma que este cálculo contemplasse a matrícula real do ano vigente. Em função disso, informam que, muitas vezes, ocorre a necessidade de administrar um montante de recursos reduzido frente ao número de alunos matriculados.

Acerca dos valores monetários per capita com que as escolas visitadas contam para a alimentação escolar, tem-se: Escola 1 ( $\mathrm{R} \$$ 1,41); Escola 2 ( $\mathrm{R} \$ 2,24)$; Escola 3 ( $\mathrm{R} \$ 1,92)$; Escola 4 (R\$ 1,87); Escola 5 (R\$2,08); Escola 
6 (R\$ 2,84); Escola 7 (R\$ 1,74); Escola 8 (R\$ 2,60); Escola 9 (R\$ 1,00); Escola 10 (R\$ 2,12); Escola 11 (R\$ 4,27); Escola 12 (R\$ 1,35); Escola $13(\mathrm{R} \$ 1,16)$ e Escola $14(\mathrm{R} \$ 2,87)$. A discrepância nesses valores é vislumbrada na escola 11 que conta com um reduzido número de alunos (281), em particular observa-se que esta escola conta com um expressivo número de doações de alimentos, que permite a não utilização da totalidade dos recursos, o que explica o valor per capita mais elevado.

As escolas realizam uma prestação de contas semestral mediante apresentação documental de todo processo licitatório de compra e venda dos produtos da merenda escolar. Constata-se que seis escolas não são fiscalizadas pelas entidades competentes para verificar se as diretrizes norteadoras do Programa são cumpridas. Em oito escolas, os responsáveis informaram que em períodos anteriores teriam recebido visitas de encarregados pela fiscalização dos procedimentos do Programa.

A pesquisa mostra ainda que dentre as maiores dificuldades enfrentadas pelas escolas com relação ao PNAE, estão: a) o atendimento à legislação intrínseca ao Programa; b) prestar contas em função de toda burocracia que envolve o processo; c) a falta de estrutura adequada para realizar a merenda escolar; d) o baixo valor monetário repassado em relação ao número de alunos; e e) a falta de opção de onde e de quem comprar os produtos para alimentação dos escolares. Neste sentido, enfatizam que a atuação do Estado é precária, sendo que em dez escolas o Estado não teria fornecido as condições necessárias para que pudessem cumprir as normas e diretrizes do PNAE, conforme vislumbrado no Quadro 1. Ressalta-se que em duas escolas os entrevistados afirmaram não ter grandes dificuldades com relação ao Programa.

Quadro 1 - PrincipaIS DIFICULDAdes ENFRENTADAS

PELAS ESCOLAS EM RELAÇÃO AO PNAE.

\begin{tabular}{|c|c|}
\hline PRINCIPAIS DIFICULDADES & FREQUÊNCIA \\
\hline Atender a legislação do Programa & 3 \\
\hline Prestar contas & 1 \\
\hline Falta de estrutura adequada & 3 \\
\hline Valor repassado é baixo pelo número de alunos & 3 \\
\hline Falta opção de compra para os produtos & 2 \\
\hline
\end{tabular}

Outro fato revelado pela pesquisa que merece destaque é que as escolas comportam uma infraestrutura precária para realizar a merenda. Apesar desse fato não impedir que os alunos tenham acesso à alimentação escolar, isto impede uma forma mais adequada contemplar os objetivos do Programa no que concerne à manutenção qualitativa dos produtos in natura.

\section{CONSIDERAÇÕES FINAIS}

Este artigo teve por objetivo mostrar a dinâmica operacional do Programa Nacional de Alimentação Escolar (PNAE) nas escolas estaduais do município de Santa MariaRS. Neste sentido, pôde-se perceber que as diretrizes mais gerais que norteiam a conduta nos diferentes níveis de operacionalização do PNAE são verificadas no âmbito das escolas analisadas na pesquisa. Verificou-se que na percepção dos entrevistados, uma das maiores deficiências logísticas das escolas diz respeito à falta de infraestrutura adequada para atender às necessidades de utilização de alimentos in natura para posterior processamento. Se tais condições fossem cumpridas, não apenas os alunos teriam uma alimentação mais adequada em termos nutricionais, mas, também, a outra ponta (os agricultores familiares) teria uma inserção mais efetiva no Programa.

No que tange ao PNAE como um mercado institucional, este representa uma oportunidade concreta de geração de renda para os empreendimentos da agricultura familiar, visto que propõe a garantia da existência de uma demanda para os produtos dos empreendimentos rurais de base familiar. Neste sentido, a compra institucional da merenda escolar possibilita o fortalecimento dos empreendimentos rurais e também uma alimentação saudável e segura para os escolares, tendo em vista os pilares que sustentam o conceito de segurança alimentar e nutricional, sendo esta uma das bases que norteiam o Programa.

O estudo apresentou como principal limitação a dificuldade de acesso às escolas, 
uma vez que algumas delas não demonstraram interesse em participar da pesquisa. Como contribuições, sustenta-se que analisar programas institucionais que atuem no âmbito da evolução social e econômica é fundamental em virtude da importância socioeconômica inerente a essas iniciativas, de modo que as pesquisas realizadas neste âmbito poderão servir de base para o aprimoramento de políticas complementares e incursões específicas em elementos infraestruturais, permitindo uma melhor qualidade na merenda escolar e implicando em melhorias para todos os segmentos sociais envolvidos.

Em decorrência do excesso de burocratização intrínseco à operacionalização do PNAE, muitos agricultores não conseguem se inserir no Programa, assim como muitas escolas também apresentam dificuldades com relação ao atendimento de suas normas.

Assim, sugere-se que o processo de compra e venda seja rearticulado, de modo que permita que se opere com menor complexidade, tendo em vista cumprir a proposta de aproximar a produção da agricultura familiar e a alimentação escolar (produtor e consumidor), sendo valorizada a produção local. Certamente, isso se tornará possível com o aprimoramento do Programa, que em termos estruturais apresenta-se como recente.

A teoria institucional, dentre outras contribuições, preconiza a ideia de ênfase na coordenação das instituições envolvidas já que reúne diversos atores. O PNAE é uma experiência que almeja, além de criar demanda para a produção da agricultura familiar e, dessa forma, estimular o desenvolvimento local e regional fortalecendo os empreendimentos rurais, proporcionar uma alimentação saudável e segura em consonância com os princípios basilares que norteiam o ideário de segurança alimentar e nutricional.

Recebido em: 13/03/2016

Aprovado em: 02/05/2016

\section{REFERÊNCIAS}

ACEMOGLU, D. Technical Change, Inequality, and The Labor Market. Journal of Economic Literature, v. 40, mar. p. 7-72, 2002.

ARBAGE, A. P. Economia Rural: conceitos básicos e aplicações. ed. atual. Chapecó: Argos, 2003.

BUAINAIN, A. M.; ROMEIRO, A. R.; GUANZIROLI, C. Agricultura familiar e o novo mundo rural. Sociologias, Porto Alegre, 2003, n.10, p. 312-347, jul./dez. 2003.

BRASIL. Lei n. 11.326/2006, de 24 de julho de 2006. Estabelece as diretrizes para a formulação da política nacional da agricultura familiar e empreendimentos familiares rurais. Diário Oficial [da] República Federativa do Brasil, Brasília, DF, 25 jul. 2006. Disponível em: <https://www.planalto.gov.br/ccivil_03/ Ato2004-2006/2006/Lei/L11326.htm > . Acesso em: 11 abr. 2014.

BRASIL. Lei n. 11.947/2009, de 16 de junho de 2009. Dispõe sobre o atendimento da alimentação escolar e do programa dinheiro direto na escola aos alunos da educação básica, altera a lei $\mathrm{n}^{\circ} 10.880$, de 9 de junho de 2004, 11.273, de 6 de fevereiro de 2006, 11.507, de 20 de julho de 2007; revoga dispositivos da medida provisória $\mathrm{n}^{\circ}$ 2.178-36, de 24 de agosto de 2001, e a lei $\mathrm{n}^{\circ} 8.913$, de 12 de julho de 1994; e dá outras providências. Diário Oficial [da] República Federativa do Brasil, Brasília, DF, 17 jun. 2009. Disponível em <http://www.planalto.gov.br/ccivil_03/ ato2007-2010/2009/lei/111947.htm>. Acessoem 11 abr. 2014.

FUNDO

NACIONAL

DE

DESENVOLVIMENTO DA EDUCAÇÃO (FNDE). PNAE. Disponível em: < http://www. fnde.gov.br/programas/alimentacao-escolar/ alimentacao-escolar-apresentacao $>$. Acesso em 08 abr. 2014.

FUNDO NACIONAL DE DESENVOLVIMENTO DA EDUCAÇÃO (FNDE). PNAE. Disponível em: <http:// www.fnde.gov.br/programas/alimentacaoescolar/alimentacao-escolar-funcionamento/ execu $\%$ C3\%A7\%C3\%A3o-alimentacao > . Acesso em 10 abr. 2014. 
BRASIL. Ministério da Educação. Publicações -SEB. Disponível em: < http://portal.mec.gov. br/seb/arquivos/pdf/profunc/12_pol_aliment_ escol.pdf $>$. Acesso em: 23 jun. $201 \overline{4}$.

CERVO, A. L.; BERVIAN, P. A. Metodologia Científica. 3. ed. São Paulo, McGraw-Hill, 1983.

COMMONS, J. R. Institutional Economics: Vol. I: Its Place in Political Economy. Transaction Publishers, New York, Macmillan, 1934.

CONSELHO NACIONAL DE SEGURANÇA ALIMENTAR E NUTRICIONAL (CONSEA). Conceitos. Disponível em: <http:// www3.planalto.gov.br/consea/o-conselho/ conceitos-1>. Acesso em: 22 jun. 2014.

CONCEIÇÃO, O. A. C. O conceito de instituição nas modernas abordagens institucionalistas.

Revista de Economia Contemporânea, Rio de Janeiro, v. 6, n. 2, p. 119-146, jul./dez. 2002.

FIANI, R. Teoria dos Custos de Transação. In: KUPFER, D.; HASENCLEVER, L. (Org.). Economia Industrial: fundamentos teóricos e práticas no Brasil. Rio de Janeiro: Elsevier, 2002, cap. 12, p. 267-286.

GREIF, A. Contract Enforceability and Economic Institutions in Early Trade: The Maghribi Trader's Coalition. The American Economic Review, v. 83, n. 3, p. 525-548, jun. 1993.

GIL, A. C. Como elaborar projetos de pesquisa. 5. ed. São Paulo: Editora Atlas S.A., 2010.

HUSENOV, B; MAKHKAMO, M; GARKAVAGUSTAVSSON, L; MUMINJANOV, H; JOHANSSON, E. Breeding for wheat quality to assure food security of a staple crop: the case study of Tajikistan. Agriculture \& Food Security, v. 4, n. 9, p. 2-8, 2015.

MARCONI, M. A; LAKATOS, Eva Maria. Técnicas de pesquisa. 7. ed. São Paulo: Editora Atlas S.A., 2009.

MARSDEN, T. Third Natures? Reconstituting Space through Placemaking Strategies for Sustainability. International Journal of Sociology of Agriculture and Food, v. 19, n. 2, p. 257-274, may. 2012.
MEDEIROS, C. A. de. Instituições, Estado e Mercado no Processo do Desenvolvimento Econômico. Revista de Economia Contemporânea, Rio de Janeiro, v. 5, n. 1, p. 49-76, jan./jun. 2001.

SARAIVA, E. B. et al. Panorama da compra de alimentos da agricultura familiar para o Programa Nacional de Alimentação Escolar. Ciência e Saúde Coletiva, v. 18, n. 4, p. 927 935, 2013.

SAES, M. S. M. Organizações e Instituições. In: ZYLBERSZTAJN, D.; NEVES, M. F. (Org.). Economia e Gestão dos Negócios Agroalimentares. São Paulo: Pioneira Thomson Learning, 2005, cap. 8, p. 165-186.

SCHMITT, C. J.; GRISA, C. Agroecologia, mercados e políticas públicas: uma análise a partir dos instrumentos de ação governamental. In: NIEDERLE, P. A.; ALMEIDA, L. de; VEZZANI; F. M. (Org.). Agroecologia: práticas, mercados e políticas para uma nova agricultura. Curitiba: Kairós, 2013, parte 2, p. 215-265.

SCHIMITT, C. J.; GUIMARÃES, L. A. O mercado institucional como instrumento para o fortalecimento da agricultura familiar de base ecológica. Revista Agriculturas, Rio de Janeiro, v. 5, n. 2, p. 7-13, jun. 2008.

SCHIMITT, C. J. Aquisição de alimentos da agricultura familiar: Integração entre política agrícola e segurança alimentar e nutricional. Revista de Política Agrícola, Brasília, DF, v. 14, n. 2, p. 78-88, abr./mai./jun. 2005.

SILVA, S. P. Políticas públicas, agricultura familiar e desenvolvimento territorial. Cadernos Gestão Pública e Cidadania, São Paulo, v. 16, n. 58, 2011.

SILVA, M. G. da.; SILVA, S. P. Para além do acesso: Um análise da relação entre mercados institucionais e empreendimentos de economia solidária no meio rural. In: Mercado de Trabalho: Conjuntura e Análise. Brasília: IPEA, v. 16, n. 49, p. 87-93, nov. 2011.

SIMÕES, A. Instituições e desenvolvimento econômico: os contrastes entre as visões da Nova Economia Institucional (NEI) e dos neoinstitucionalistas. Ensaios FEE, Porto Alegre, v. 35, n. 1, p. 33-54, jun. 2014. 
VEBLEN, T. The Theory of Business Enterprise. New York: Charles Scribner's Sons, 1904.

VIEIRA. A. C. P. et al. Mecanismos organizacionais como resposta à informação imperfeita: a questão da segurança dos alimentos. Informações Econômicas, São Paulo, v. 37, n. 9, set. 2007.

VILLAR, B. S. et al. Situação dos municípios do estado de São Paulo com relação à compra direta de produtos da agricultura familiar para o Programa Nacional de Alimentação Escolar (PNAE). Revista Brasileira Epidemiol, v. 16, n.1, p. 223-226, 2013.

ZYLBERSZTAJN, D. Conceitos Gerais, Evolução e Apresentação do Sistema Agroindustrial. In: ZYLBERSZTAJN, D.; NEVES, M. F. (Org.). Economia e Gestão dos Negócios Agroalimentares. São Paulo: Pioneira Thomson Learning, 2005, cap. 1, p. 1-21. 